\title{
Multiple Technique Characterization of a Nanostructured Ferritic Alloy: Heat- to-Heat, Long Term High Temperature Thermal Aging and Friction Stir Welding Effects on Nano-Scale Dispersion Strengthening Features
}

\author{
G. R. Odette*, N. J. Cunningham*, Y. Yu*, A. Etienne*, E. Haney* and T. Yamamoto* \\ * Department of Mechanical Engineering and Department of Materials, University of California \\ Santa Barbara, Santa Barbara, CA 93106
}

Nano-structured ferritic alloys (NFA) have high tensile and creep strength permitting operation up to $800^{\circ} \mathrm{C}$ or more, manifest remarkable resistance to radiation damage and can manage high concentrations of helium [1]. These outstanding properties derive from an ultrahigh density of Ti-Y$\mathrm{O}$ enriched nano-features (NF) that provide dispersion strengthening, help stabilize dislocation and fine grain structures, reduce excess concentrations of displacement defects by enhancing vacancyself-interstitial recombination and trap helium in fine, and relatively harmless, bubbles [1]. NFA are typically processed by mechanical alloying (MA) rapidly solidified metallic powders with $\mathrm{Y}_{2} \mathrm{O}_{3}$ by ball milling. The $\mathrm{Y}$ and $\mathrm{O}$ dissolve in the Fe-Cr-W-Ti matrix, subsequently precipitating along with Ti during hot consolidation. We have previously shown that the characteristics of the NF primarily depend on the consolidation (or powder annealing) time-temperature history and alloy composition [2]. Further, we previously described a round-robin multi-institution, multi technique study of a reference commercial vendor NFA, MA957 [presented at M\&M 2009].

We report additional multi-technique characterization studies on several variants of MA957, including: an as-extruded bar US heat; an extruded thick walled tube French heat; a friction stirred weld (FSW); and high temperature - long time thermal aging conditions. The techniques include small angle neutron scattering (SANS), a variety of transmission electron microscopy (TEM) techniques and atom probe tomography (APT). Note this work is in progress and the specific numbers cited below are subject to change based on ongoing measurements and analysis.

The previous inter-comparison study of the US MA957 showed generally excellent agreement for the size $(<d>)$, number density $(\mathrm{N})$ and volume fractions (f) of the small NF, within uncertainties in the techniques and expected in and between specimen variations. However, APT measurements consistently indicated NF compositions with low $\mathrm{Y} / \mathrm{Ti}$ and $\mathrm{O} /(\mathrm{Y}+\mathrm{Ti})$ ratios compared to stoichiometric complex oxides like $\mathrm{Y}_{2} \mathrm{Ti}_{2} \mathrm{O}_{7}$ and $\mathrm{Y}_{2} \mathrm{TiO}_{5}$. In contrast, SANS measurements were consistent with a mix of complex oxides. Scanning probe TEM (STEM) energy dispersive x-ray spectra (EDS) measurements on $\mathrm{C}$ extraction replicas at larger NF sizes $(>5 \mathrm{~nm})$ showed more stoichiometric $\mathrm{Y} / \mathrm{Ti}(\approx 1.5)$ ratios and higher $\mathrm{O} /(\mathrm{Y}+\mathrm{Ti})$ ratios compared to the APT results. High resolution TEM (HTEM) fast Fourier indexing of the larger particles was generally found to be most consistent with $\mathrm{Y}_{2} \mathrm{TiO}_{5}$. Since then indexing and EDS measurements have been extended to smaller $\mathrm{NF}(<5 \mathrm{~nm})$ with generally similar results. However, it was more difficult to carry out structural and compositional characterization in this size range, and it may be notable that single lattice spacing imaging was not consistent with either $\mathrm{Y}_{2} \mathrm{Ti}_{2} \mathrm{O}_{7}$ or $\mathrm{Y}_{2} \mathrm{TiO}_{5}$ in a number of cases. High angle annular dark field (HAADF) STEM characterization of the extraction replicas was used to characterize NF size distributions. As illustrated in Figure 1, HAADF imaging also clearly reveals complex features, composed of various precipitates that form in association with one another. The morphologies of the associated features range from very small NF on the surface of slightly larger precipitates, to large agglomerated clumps of many precipitates on larger length scales. The number densities of the 
associated features are about an order of magnitude less that for isolated NF. However, they may play an important role in the high temperature properties of NFA.

US and French Heats of MA957: SANS shows an average NF $\mathrm{N} \approx 9.3 \times 10^{23} / \mathrm{m}^{3},<\mathrm{d}>\approx 2.4 \mathrm{~nm}$ and $\mathrm{f}$ $\approx 0.92 \%$ in the US heat of MA957 compared to $\mathrm{N} \approx 7.6 \times 10^{23} / \mathrm{m}^{3},<\mathrm{d}>\approx 2.6 \mathrm{~nm}$ and $\mathrm{f} \approx 0.72 \%$. for the French heat. There is a larger difference between the magnetic to nuclear scattering $\operatorname{ratios}(\mathrm{M} / \mathrm{N})$ in the US $(\approx 1.9)$ versus French $(\approx 1.1)$ heats, indicating possible differences in the NF compositionstructure; note another US MA957 heat also had a low $\mathrm{M} / \mathrm{N} \approx 1.2$ [2]. HAADF showed slightly lower NF number densities and larger sizes $(<\mathrm{d}>\approx 3.8 \mathrm{~nm})$ than SANS in both heats. APT measurements on the US heat showed larger variations on the NF populations, with average $\mathrm{N} \approx$ $5 \times 10^{23} / \mathrm{m}^{3}$ and $<\mathrm{d}>\approx 2.3 \mathrm{~nm}$. Thus it appears that the TEM may miss some of the smaller NF.

Thermally Aged MA957: We have continued long-term, high-temperature aging study [4] of MA 957 from $800^{\circ} \mathrm{C}$ to $1000^{\circ} \mathrm{C}$ up to $19 \mathrm{kh}$. SANS measurements show the NF gradually coarsen at $1000^{\circ} \mathrm{C}$. There also appears to be some recovery of the elongated grains into a more equiaxed configuration at $1000^{\circ} \mathrm{C}$. The hardness decreases by $\approx 5$ and $12 \%$ at 950 and $1000^{\circ} \mathrm{C}$, respectively, at $19 \mathrm{kh}$. HAADF imaging shows no change in the NF $<\mathrm{r}>$ and a slight increase in $\mathrm{N}$ after19 kh at $1000^{\circ} \mathrm{C}$, possibly due to an increase in the HAADF visibility. There may be an increase in the presence of agglomerated features. APT studies are planned.

Friction Stir Welds (FSW): Previous SANS and TEM studies on a US MA957 FSW produced by the Edison Welding Institute [5] showed that severe deformation reduced, but did not eliminate the NF . A recent APT study confirmed and further quantified these previous observations, showing $\mathrm{N} \approx$ $1.5 \times 10^{23} / \mathrm{cm}^{3} \mathrm{NF}<3 \mathrm{~nm}$ and a population of $\mathrm{N} \approx 2.8 \times 10^{21} / \mathrm{m}^{3}$ larger features $>5 \mathrm{~nm}$. The Y/Ti and $\mathrm{O} /(\mathrm{Ti}+\mathrm{Y})$ ratios were higher in the larger features, but still below stoichiometric values.

\section{References}

[1] G.R. Odette, M.J. Alinger, B.D. Wirth, Annual Review of Materials Research 38 (2008) 471.

[2] M. J. Alinger, G. R. Odette, D.T. Hoelzer, Acta Mater. 57 (2009) 392.

[3] P. Miao, G. R. Odette and T. Yamamoto, J. Nuc. Mat. 337-1 (2008) 59.

[4] P. Miao, G. R. Odette, J. Gould, et al., J. Nuc. Mat. 367 (2007) 1197

[5] This research was supported by the DOE Offices of Fusion Energy Sciences and Nuclear Energy
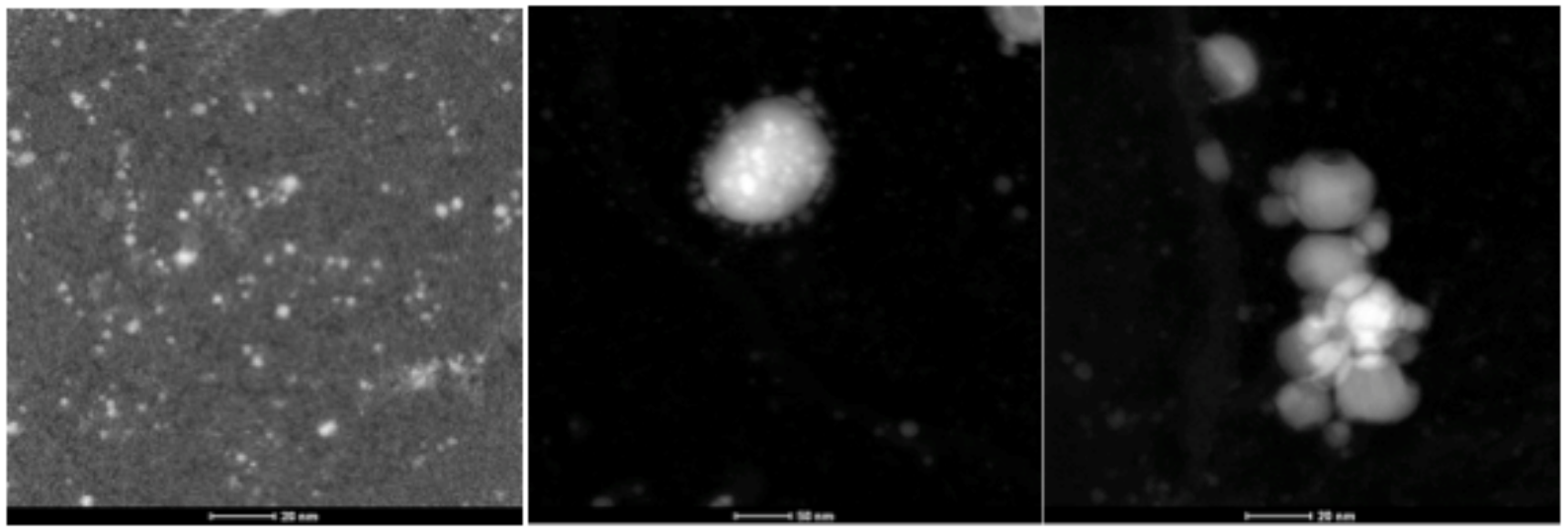

Fig. 1. Examples of isolated NF (left), associated features (middle) and agglomerated features (right). 